\title{
BuildCOM: automated auditing and continuous commissioning of next generation building management systems
}

Muhyiddine Jradi ${ }^{1 *}$ (D, Niels Boel ${ }^{2}$, Bo Eskerod Madsen ${ }^{3}$, Jonas Jacobsen ${ }^{4}$, Julie Strandesen Hooge ${ }^{5}$ and Lars Kildelund ${ }^{6}$

\author{
* Correspondence: mjr@mmmi.sdu. \\ dk \\ Additional information on the \\ project details, activities and \\ products can be found here: \\ https://www.sdu.dk/en/forskning/ \\ centreforenergyinformatics/ \\ research+projects/buildcom or by \\ direct contact to the corresponding \\ author. \\ ${ }^{1}$ Center for Energy Informatics, \\ Mærsk McKinney Møller Institute, \\ University of Southern Denmark, \\ Campusvej 55, DK-5230 Odense M, \\ Denmark \\ Full list of author information is \\ available at the end of the article
}

\begin{abstract}
A building management system (BMS) is generally defined as the 'Brain' of the building. Building management systems aid in improving occupant comfort and productivity and, enhance the operational efficiency of building energy generation and supply systems. This paper presents the BuildCOM project which is driven by the industry and customer needs. It responds to the increasing demands for energy efficiency, comfort, and safety in the buildings sector. The project brings together academic researchers, industrial companies and public partners, to develop and demonstrate an innovative first-of-its-kind software for BMS automated auditing and continuous building commissioning. The software has three major capabilities, initial BMS auditing, BMS retro-commissioning and continuous building commissioning. Thus, the proposed software will aid the design, development and operation of next generation building management systems. The project builds up partly on the online building energy performance monitoring and evaluation (ObepME) tool developed in COORDICY which will be combined with a holistic process for building management systems auditing and commissioning within the developed software solution. The set of tools developed under BuildCOM will be implemented and demonstrated considering multiple case studies. Implementing the proposed solution, the customers and building owners will have up to 35\% higher energy efficiency in newly built and exiting buildings, around 25\% lower operation costs and less emissions from day one and throughout the building operation phase.
\end{abstract}

Keywords: Building management system, BMS, Commissioning, Auditing, Energy efficiency

\section{Introduction}

To increase the efficiency of the energy sector and reduce carbon dioxide emissions, it is vital to have energy efficient buildings with high performance and low energy consumption and corresponding emissions. A building management system (BMS) is generally defined as the 'Brain' of the building (Evchina \& Lastra, 2018). Building management systems aid in improving occupant comfort and productivity and, enhance the operational efficiency of building energy generation and supply systems. A

(c) The Author(s). 2021 Open Access This article is licensed under a Creative Commons Attribution 4.0 International License, which permits use, sharing, adaptation, distribution and reproduction in any medium or format, as long as you give appropriate credit to the original author(s) and the source, provide a link to the Creative Commons licence, and indicate if changes were made. The images or other third party material in this article are included in the article's Creative Commons licence, unless indicated otherwise in a credit line to the material. If material is not included in the article's Creative Commons licence and your intended use is not permitted by statutory regulation or exceeds the permitted use, you will need to obtain permission directly from the copyright holder. To view a copy of this licence, visit http://creativecommons.org/licenses/by/4.0/. 
BMS is an integrated building automation and energy management system. It is fully capable of monitoring the energy performance of buildings, managing and controlling the different building services, including mechanical and electrical systems, and it establishes smooth interaction between various building components and units. However, confidence at the building design stage and simply claiming that the BMS will operate properly, and that its various functions thus will improve the energy efficiency of the building compared to reference numbers, doesn't ensure proper operation of the different systems and components (Zou et al., 2019; Frei et al., 2017). Generally, there is a clear mismatch between the actual energy performance of a building and the expected levels, referred to as the 'building performance gap' (de Wilde, 2014; Niu et al., 2016; Jradi et al., 2020).

Today, commissioning of BMS is done manually and is therefore expensive and error-prone (Rotger-Griful et al., 2017). There is a large potential in implementing initial commissioning and auditing of newly installed BMS, especially in view of the new Directive (EU) 2018/844 (European Commission, 2018) which requires that all nonresidential buildings shall be equipped with BMS by 2025. Retro-commissioning of upgraded existing building management systems has an equivalent importance. Generally, as the building goes into the operation phase, major modifications could happen. This includes upgrading of building services and components, installing new automation and control devices, modification in the building automation and management strategy and upgrades in the software and hardware components of the BMS itself. Bearing in mind that any of these modifications will have a large effect on the energy performance of the building, implementing a retro-commissioning and auditing of the BMS is indispensable to ensure a proper function of different features and smooth integration of various systems and devices. Currently, retro-commissioning of the BMS is often either insufficiently comprehensive in its execution, limited to the level of the modification occurring, or it is not conducted at all (Markoska et al., 2016). Moreover, considering the increasing complexity of building automation systems and the growing integration of IoT (Internet of Things) and intelligent devices along with the advanced and smart self-governing devices and controls, a systematic and automated building management systems initial and retro- commissioning process along with a comprehensive continuous commissioning framework is needed to aid the development and operation of next generation building management systems.

Highlighting the timeliness of the current project, a large block of recent investigations and studies was reported in the literature dealing with various aspects of building automation and control systems (BACS), mainly BMS auditing and commissioning (Aste et al., 2017; Ma et al., 2016; Domingues et al., 2016). In their study, (Ippolito et al., 2014) highlighted the importance of BACS, presenting a new method for impact evaluation and considering a case study in Italy. The authors consider European standard EN 15232 as a basis and presents the BAC factor method to quantify the impact of the BMS upgrade on the building performance. The results reported an improvement in the overall buildings EPC class when technical building management strategies are implemented, where the economic savings are largely related to the climatic conditions where the specific building is lying and the energy prices. In a similar study, Ożadowicz et al. (Ozadowicz \& Grela, 2017; Ożadowicz \& Grela, 2016) studied the impact of proper BMS upgrade and commissioning from a Polish perspective. They reported an 
enhancement in the building energy efficiency and a reduction in the overall energy consumption as a result of an upgraded and properly commissioned BMS. In addition, Mancini et al. (Mancini et al., 2019) collected data from 412 buildings where building management systems are either newly implemented or upgraded. They evaluated the impact of the various BMS control strategies on the energy savings and highlighted that demand response patterns are among the optimal strategies to play a role in a predicted future with smart grids. Overall, they reported a payback period between 7 and 10 years, depending on the building management system type and complexity. In terms of approaches and methodologies for BMS auditing and commissioning, Schönenberger (Schönenberger, 2015) presented the design of a European tool by the European building automation and control association, the eu.bac System audit tool. The tool aims towards auditing building management systems through evaluating various building systems and domains, reporting a building rating over 100 based on points rewarded for each system. Moreover, a recent qualitative multi-criteria points type evaluation framework for building automation systems auditing and initial commissioning named Smart Readiness Indicator (SRI) was introduced by the European Commission (Smart Readiness Indicator for Buildings, n.d.; Vigna et al., 2020). The assessment evaluates around 120 building services listed under various building technical domains and yields a single score between 0 and 100\%. The SRI score highlights the capability of the building automation system to provide energy efficiency, flexibility, comfort and information for occupants.

Considering the recent efforts towards digitalization of the overall energy sector and the dramatic evolution in the field of smart buildings and different aspects of building automation and control systems, the BuildCOM project will advance the state-of-theart by developing and demonstrating an innovative software for building management systems automated auditing and continuous building commissioning (AC-BMS). The developed software will thus have three capabilities and features, initial and retrocommissioning of the BMS in addition to continuous building commissioning. An overall framework of the software is shown in Fig. 1 below.

The project is an industry driven, but university headed energy development and demonstration project. It started on October 1'st 2019 and will run for 3 years, with a collaboration between three industrial companies, a public hospital, a municipality and a university. It is funded by the Danish Energy Agency under the Energy Technology Development and Demonstration Program (EUDP Project no 64019-0081).

\section{State of the art}

Commissioning is a process that is primarily performed at the end of the building construction. By that point, the building has been fully constructed, and the installation of

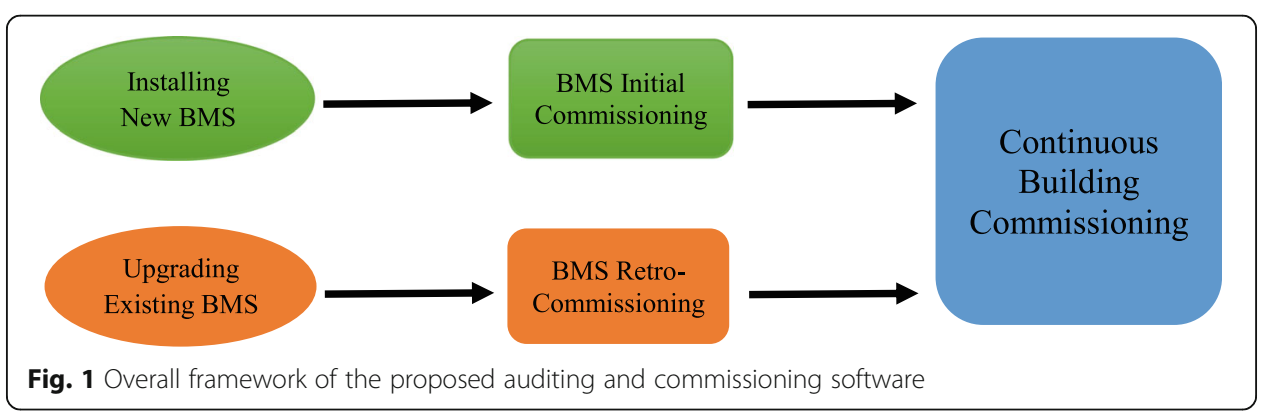


the different subsystems in the building has been completed. The International Energy Agency's (IEA) Annex 40 (American Society of Heating, Refrigerating, AirConditioning Engineers, 2006) has defined building commissioning as being a "qualityoriented process for achieving, verifying and documenting whether the performance of a building's systems and assemblies meet defined objectives and criteria". The process of commissioning brings forth a set of performance tests that are intended to verify whether the resulting building with its corresponding systems complies with the requirements stated in the design phase. These tests include, among others, verifying that the subsystems are functional and ensuring that the construction of the building itself is of satisfactory quality. The importance of building commissioning is immense, seeing as there is a multitude of regulations imposed by government agencies all over the world. These regulations involve a variety of safety measures, as well as rules about compliance to energy efficiency requirements. The strict energy efficiency and environmental requirements highlight the importance and urgency of continuous building commissioning and performance testing. Building commissioning at the end of the construction stage was found to provide substantial benefits in terms of having a smoother building start-up and enhanced occupants comfort. Nevertheless, continuous commissioning beyond this stage into the building operation phase would help to ensure long-term energy efficient performance of the building. This would provide high capabilities to implement feasible control and management strategies to improve the energy supply systems operation and thus raises the flexibility quotient of the building (GhaffarianHoseini, 2012).

The general trend in building commissioning is that commissioning is often either insufficiently comprehensive in its execution, or it is not conducted at all (Markoska et al., 2016). As such, it has been observed that buildings often will contain faults and malfunctioning systems and components that have not been discovered during the commissioning phase. Therefore, one of the main challenges facing the building stock, especially newly built energy efficient buildings, is the absence of a systematic initial commissioning process. The lack of a continuous building commissioning framework, with no performance monitoring and evaluation, leads to a building energy performance gap characterized by the overall mismatch between the predicted and the actual measured energy performance. Investigations on buildings in Denmark have reported a performance gap of up to $30 \%$ between the estimated and the actual energy consumption data (Petersen \& Hviid, 2012). While causes of energy performance gaps in buildings are interrelated and connected, they could be divided and associated to the different building phases: design phase, construction phase, and operation phase as demonstrated in Table 1 (Jradi et al., 2018).

A standard BMS is composed of software, hardware and a set of communication protocols. Such systems could serve a wide range of building sectors, from individual houses to commercial and public buildings and facilities. The promotion of worldwide digitalization means that buildings are better characterized and connected, and thus the demand for building performance monitoring and data collection is becoming essential. By utilizing IT, ICT (Information and Communications Technology) and intelligent digital communication technologies, BMS provides a holistic approach to controlling and adaptively optimizing the operation and performance of different building components. Nowadays, advanced BMS have the capability to collect and store data from submeters, sensors and actuators, carry out data and performance analysis and diagnosis, investigate trends and patterns and aid in the decision making. In addition, the BMS 
Table 1 Causes of energy performance gaps in buildings (Jradi et al., 2018)

\begin{tabular}{llc}
\hline Design Phase & Construction Phase & Operation Phase \\
\hline - building energy modeling & - mismatch between the quality at & - lack of continuous \\
limitations and uncertainties & the building handover and the & commissioning \\
- oversimplified inputs regarding the & quality at the design stage & - mismatch between design \\
built quality and fabric performance & - changing requests from clients & idealized assumptions and \\
- design complexity & - poor commissioning & actual patterns \\
- performance targets & - improper envelope assembly & - faulty systems and components \\
miscommunication & - economically driven decisions & - poor practice \\
- unrealistic early design decisions & affecting materials and systems & - lack of maintenance and service \\
- lack of integrated design principles & selection leading to design & - occupants' behavior and \\
considering energy consumption and & modifications & activities \\
indoor thermal comfort and air & - improper components and & - lack of occupancy monitoring \\
quality & systems integration & - variation in systems operation \\
- failure to predict functional and & & modes and changes in the use \\
stochastic changes & & of the building \\
- components and systems over- & & - inappropriate building \\
sizing and under-sizing & management and control \\
- lack of energy modeling and & & strategies \\
simulation knowledge and skills & & - faulty sensors and meters \\
- uncertainties and generic & & - lack of customers and residents' \\
assumptions in weather conditions, & & knowledge in terms of energy \\
occupancy patterns and behavior, & & efficiency and building \\
heat gains and plug loads & operation \\
\hline
\end{tabular}

allows a flexible and direct access to integrated automation systems in the building from various locations and platforms. Nowadays, the strict building energy efficiency regulations and standards and large initiatives to improve the energy performance of buildings in addition to the growing integration of the Internet of Things (IoT), analytics and actionable intelligence with building automation systems are driving the market growth of building management systems. In 2017, the BMS market was poised to grow at a compound annual growth rate of around $16.7 \%$ until 2023 (Building Management System Market by Software (Facility, Security, Energy, Emergency, Infrastructure Management), Service (Professional, Managed), Application (Residential, Commercial, Industrial, , n.d.), and Geography - Global Forecast). In 2023, the BMS market is expected to be valued at 19.25 billion USD, a drastic increase compared to only 6.65 billion USD in 2016. The main drivers of the BMS market growth are highlighted in Fig. 2.

In the recent Directive (EU) 2018/844 of the European Parliament and of the Council of 30 May 2018 amending Directive 2010/31/EU on the energy performance of buildings and Directive 2012/27/EU on energy efficiency, the EU have set strict requirements regarding installing and assessing Building Management Systems. The new Directive defines a building management system as being 'a building automation and control system comprising all products, software and engineering services that can support energy efficient, economical and safe operation of technical building systems through automatic controls and by facilitating the manual management of those technical building systems' (European Commission, 2018). The 2018/844 EU Directive sets strict requirements that each non-residential building in the EU member states, with an effective rated output for heating systems or systems for combined space heating and ventilation of over $290 \mathrm{~kW}$, should be equipped with a building automation and control system by 2025. In Point 37, the Directive urges the implementation of methodical and systematic commissioning of building automation systems and components as an effective replacement for inspections, where it could provide large potential for cost 


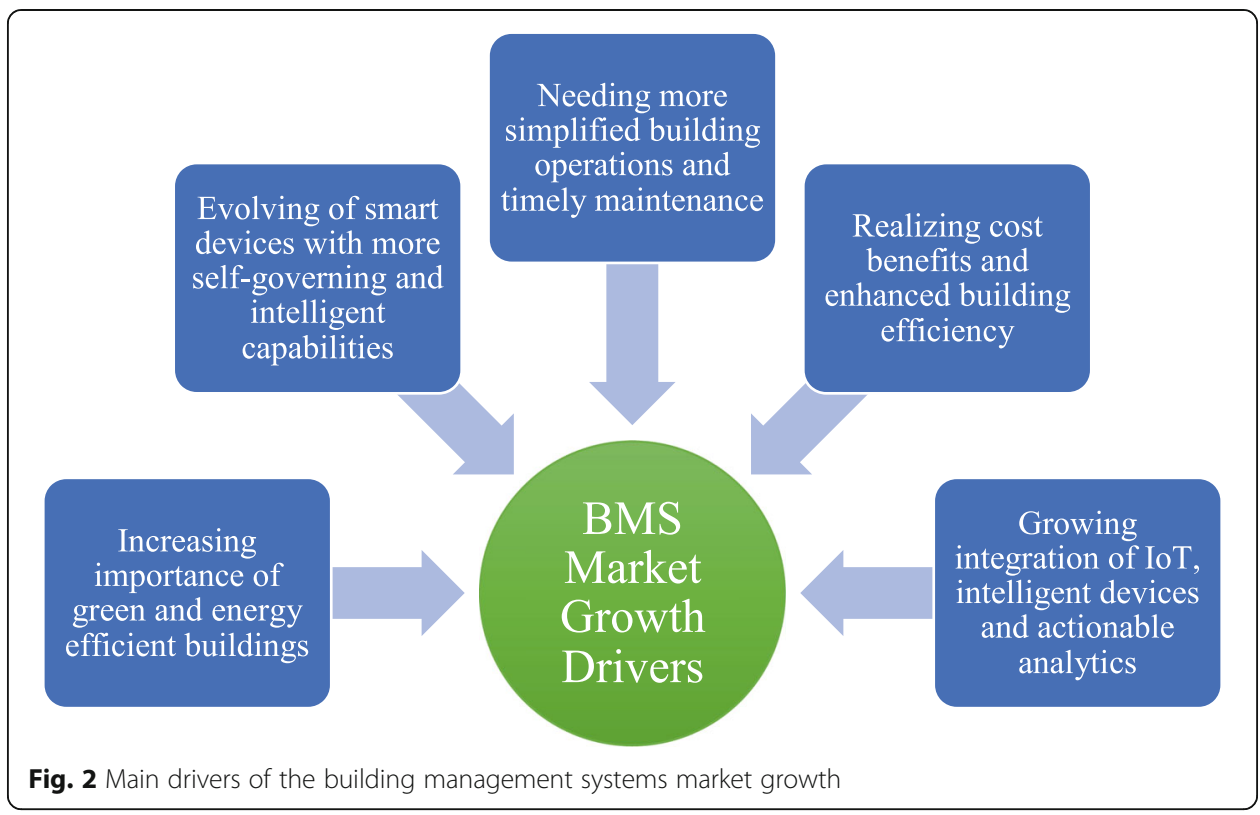

effective and significant energy savings for both consumers and businesses, specifically in large non-residential buildings.

Nevertheless, the European Standard EN 15232 "Energy performance of buildings - Impact of Building Automation, Controls and Building Management" (EN 152323 Standard, n.d.) is one of a set of CEN (Comité Européen de Normalisation, European Committee for Standardization) standards aiming to support the Directive of Energy Performance of Building (EPBD) to enhance energy performance of buildings in the EU member states. The EN15232 standard specifies methods and guidelines to assess the impact of Building Automation and Control System (BACS) and Technical Building Management (TEM) functions on buildings energy performance. In addition, it comprises a structured list of building control, automation and technical management functions to enhance the energy performance. In this context, the European Building Automation and Controls Association (eu.bac) (European Building Automation and Controls Association (eu.bac), n.d.) was founded in 2003 and represents around 95\% of the European manufacturers for home and building automation and energy service companies. Based on the EN 15232 standard, the association has developed a methodology for auditing and certifying building management systems to aid energy-efficient and optimized operation of buildings. The methodology supports a life-cycle framework including the design, commissioning and operation of energy efficient building management systems. The auditing covers various building management system services and automation functions, in particular: temperature control, indoor air quality control, lighting, heating, cooling, ventilation, domestic hot water, drivers and motors, monitoring, technical alarms and power management, diagnostic information, central operation and settings and remote controls. However, the process is done manually and only by a Certified Auditor. Figure 3 presents the eu.bac methodology for auditing and certifying building management systems based on the EN 15232 standard (Engvang \& Jradi, 2021).

In addition, a properly functioning, advanced BMS with all integrated building energy, environmental, emergency, and security operational parameters, leads to 


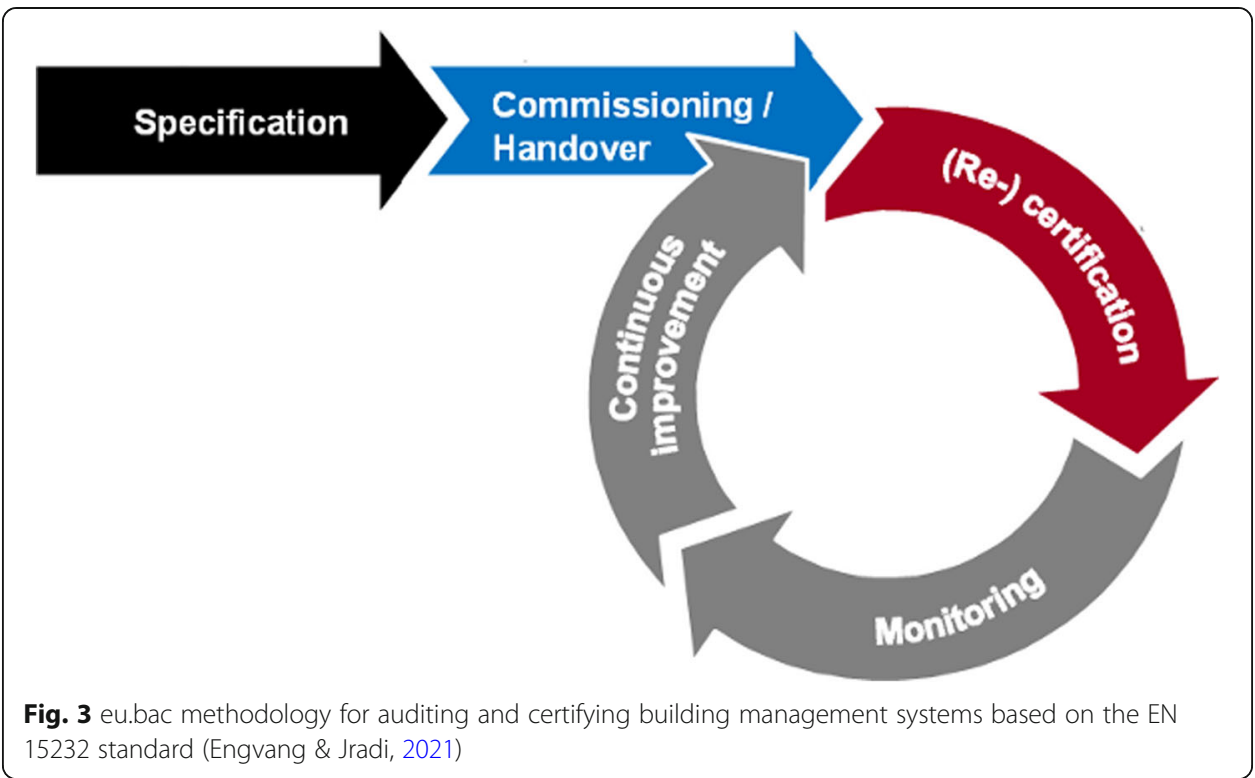

decreasing operational costs by providing huge opportunities for operators to drive performance metrics in complete alignment with business objectives for the entire buildings. Onsite data collected has shown that such integration can lead up to $24 \%$ savings in investment costs for installation and 35\% in operational costs savings over time (Holbeck, 2007). On the other hand, based on data collected from 26 non-residential building sites in the US, it was reported that implementing a proper building continuous commissioning process has the potential to save up to $35 \%$ on the building energy consumption as shown in Fig. 4, with a payback period of less than 3 years (Bynum et al., 2008). Thus, by combining BMS auditing to ensure a proper operation and integration, in addition to a holistic building continuous commissioning process, this project has a large potential for achieving major savings on the overall energy consumption with a corresponding substantial costs reduction.

Due to the added value of building management systems commissioning, there is an urgent need for a set of tools to improve and facilitate the initial commissioning process at the design and construction stages, in addition to implementing an automated continuous commissioning process that runs throughout the building operational phase. Such tools would aid in determining if the energy performance indicators are met and help in developing and implementing operational strategies to optimize the performance of different systems in the building and enhance the flexibility quotient. In addition, continuous building commissioning and energy performance monitoring is an indispensable requirement for a systematic and effective fault detection and diagnostics process for energy systems operation. This will lead to both technical and economic benefits in terms of avoiding excess energy consumption and increased operational costs due to components malfunction.

\section{Project objectives}

Building management systems became an indispensable component and a key factor towards achieving an energy efficient and smart future building stock. However, and as highlighted in the state-of-the-art review presented above, there is a lack of a 


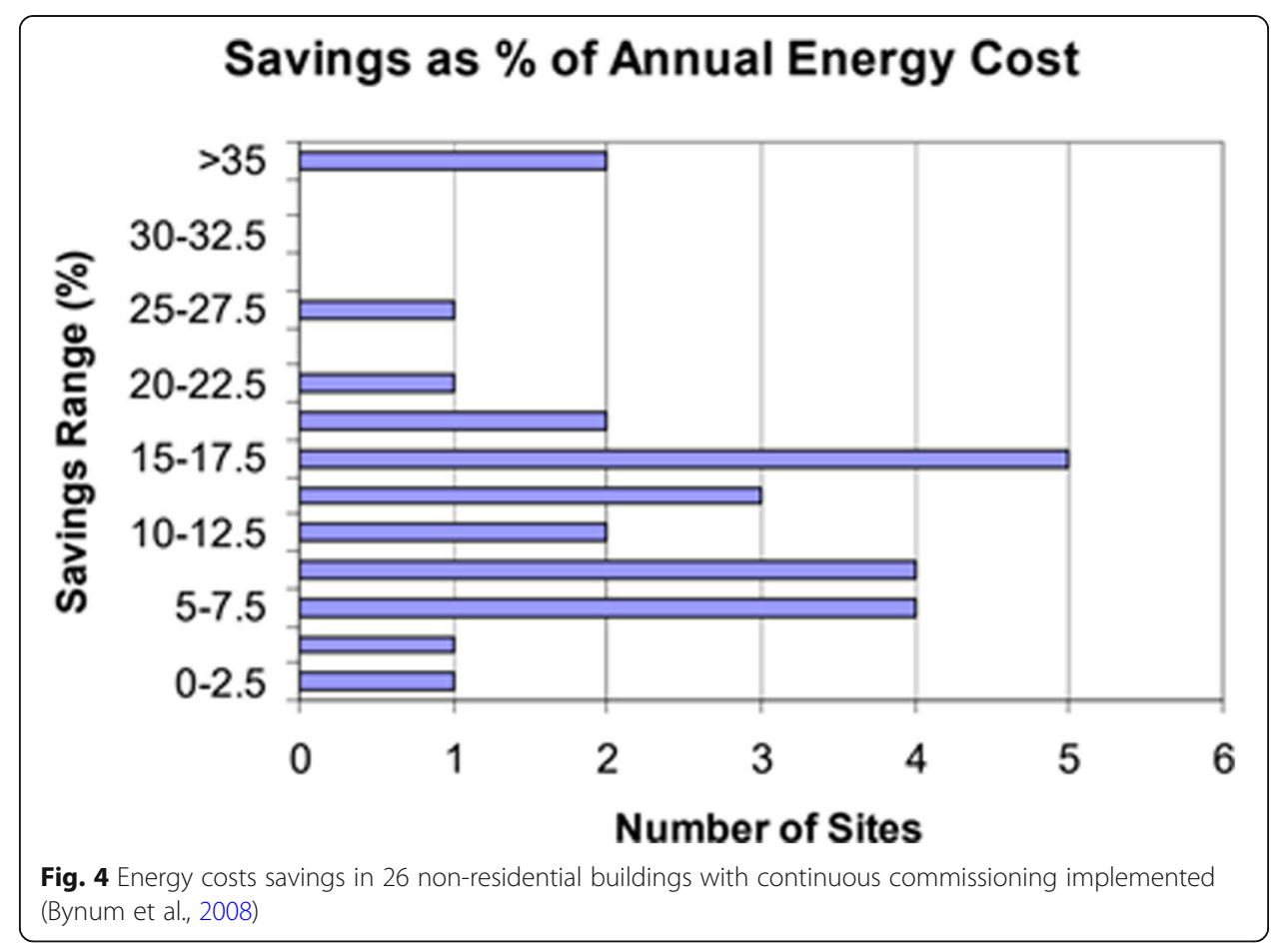

comprehensive and effective tool for building management systems auditing and smartness evaluation. In addition to rating and evaluating the current building automation system in the building, such tool will help in laying the foundation and establishing proper baseline for future building management systems design, aiding the transition towards a smart and energy efficient building sector. Moreover, the review presented above shows the added value and the urgent need for comprehensive and effective tools for proper building continuous commissioning and performance monitoring in general. Such tools will aid in reducing building performance gaps, establishing proper building operation from day one, highlighting faults and errors as soon as they happen and reducing operational and maintenance costs.

This BuildCOM project will advance the state-of-the-art through the development and demonstration of an innovative interactive and user-friendly software for building management systems automated auditing and continuous building commissioning. This first-of-its kind software will have three major capabilities and features:

1. Initial commissioning of BMS installed in newly built or existing buildings

2. Retro-commissioning of BMS upgraded and modified in existing building

3. Continuous building commissioning and performance testing throughout the operational phase of the building

As a major milestone in the innovative software development, the project will aim at the design and development of a holistic methodology for building management systems auditing to serve as a backbone for BMS initial and continuous commissioning. The methodology will include a list of the major technical specifications and functions of BMS to be audited and tested along with the evaluation and assessment criteria. 
The methodology developed will serve as the basis for a combined BMS auditing and continuous building commissioning framework and a first of its kind software with a set of tools targeting building management systems auditing, initial- and retrocommissioning as well as whole building continuous commissioning.

The building management system auditing and continuous building commissioning software developed in this project will be implemented, demonstrated and evaluated in multiple case studies to draw conclusions and recommendations for future implementations in the building sector.

\section{Project concept}

Concerning the first two software features listed above, the BMS auditing process will include both initial commissioning of newly installed BMS in newly built and existing public and commercial buildings, and retro-commissioning of upgraded and modified BMS in existing public and commercial buildings. The auditing process will be based on the requirements and regulations of the European Standard EN 15232 "Energy performance of buildings - Impact of Building Automation, Controls and Building Management" and the auditing and certifying building management systems methodology developed by the European Building Automation and Controls Association (eu.bac). The auditing covers various BMS services and automation functions, including: temperature control, indoor air quality control, lighting, heating, cooling, ventilation, domestic hot water, drivers and motors, performance monitoring, technical alarms and power management, diagnostic information, central operation and settings and remote controls.

The third software feature will allow for automated holistic continuous building commissioning and performance testing throughout the operational phase of the building. This will build on the research findings of the International Research Project COORDICY (COORDICY Project, n.d.), 'ICT-driven Coordination for Reaching 2020 Energy Efficiency Goals in Public and Commercial Buildings', in particular the development of an Online Energy Performance Monitoring and Evaluation Tool (ObepME) (Jradi et al., 2018), aiming to integrate the overall continuous commissioning tool within new AC-BMS software. The ObepME tool comprises a set of building performance tests which was developed to meet the strict Danish building regulations and energy efficiency requirements. These tests target various building subsystems including heating, ventilation and air conditioning (HVAC) components and units, to assess the building performance and ensure that the building performs as expected.

As shown in Fig. 5, the tool has two main inputs: simulations from whole-building dynamic energy performance model and actual data collected onsite from various meters and submeters in the building. Based on these two inputs, performance tests are carried out within the tool to automatically and continuously compare actual building performance to expected performance baseline set by the simulations. ObepME was developed and demonstrated within COORDICY by the Center for Energy Informatics at University of Southern Denmark in collaboration with Schneider Electric and is at TRL4. The aim is that this proposed project will develop it further to TRL8. The ObepME tool was implemented and demonstrated using the OU44 Building Living Lab at the University of Southern Denmark, Odense, as a case study (Jradi et al., 2017). The tool implementation serves as a backbone for fault detection and diagnostics and this 


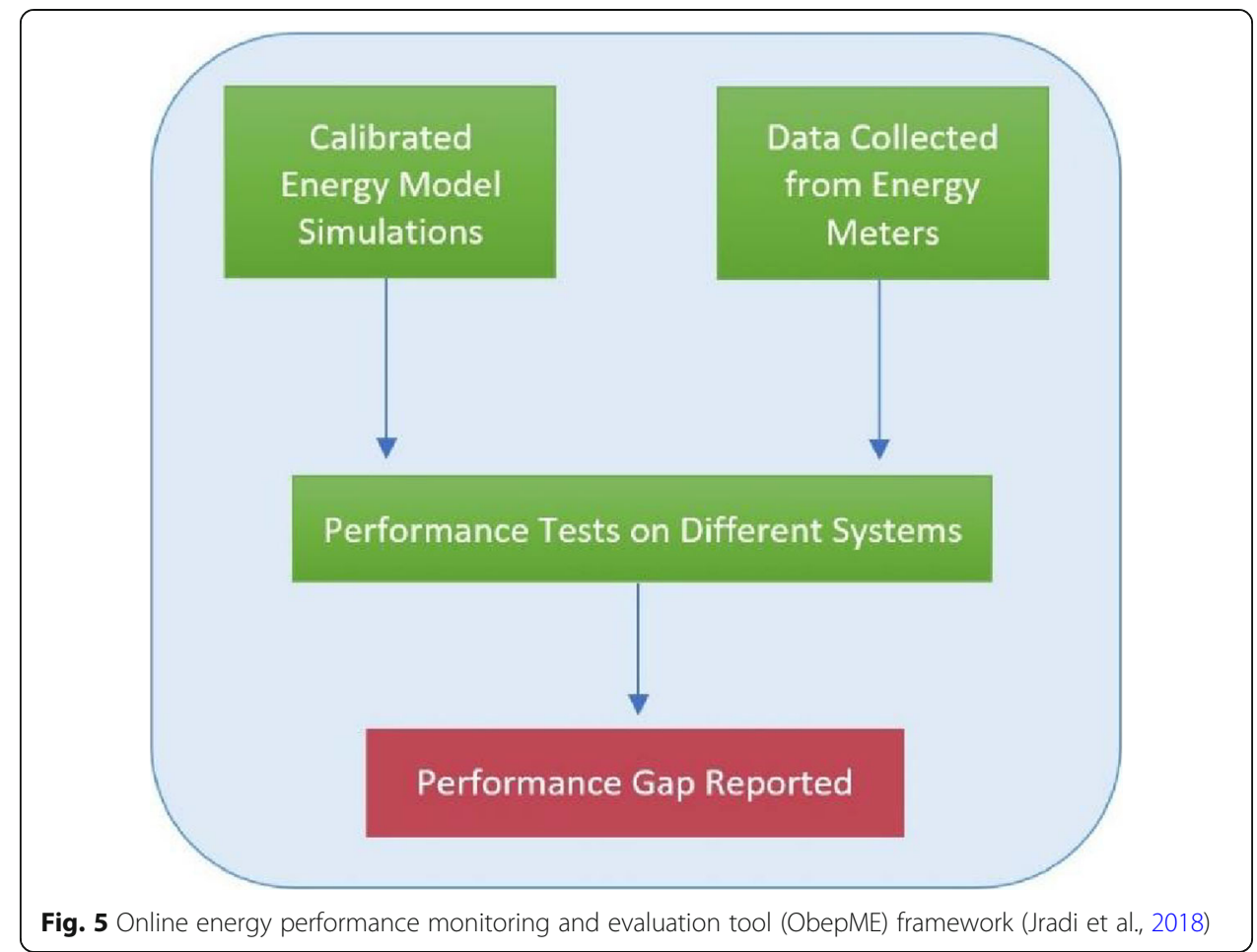

was demonstrated in different cases. For example, the tool has captured and reported a mal-functioning ventilation sub-system and based on the investigation, a VAV diffuser controller problem was highlighted which resulted in increased electricity consumption of the ventilation unit by $84 \%$. Solving the issue on time has led to an avoidable average monthly operational cost of around 2800 DKK.

$\mathrm{n}$

With its three functions, initial and retro-commissioning of the BMS and continuous building commissioning and performance testing, the software will support the Directive (EU) 2018/844 of the European Parliament and of the Council of 30 May 2018 upgrading Directive 2010/31/EU on the energy performance of buildings and Directive 2012/27/EU on energy efficiency, which sets strict specifications and capabilities of the next generation building management systems as (European Commission, 2018):

(a) continuously monitoring, logging, analysing and allowing for adjusting energy use

(b) benchmarking the building's energy efficiency, detecting losses in efficiency of technical building systems, and informing the person responsible for the facilities or technical building management about opportunities for energy efficiency improvement

(c) allowing communication with connected technical building systems and other appliances inside the building and being interoperable with technical building systems across different types of proprietary technologies, devices and manufacturers

\section{Project methodology and deliverables}

The overall project delivery is an innovative software for building management systems automated auditing and continuous building commissioning. This first-of-its kind 
software will comprise a set of tools aiming to fulfil three major tasks, 1) Initial commissioning of BMS, 2) Retro-commissioning of BMS and 3) Continuous building commissioning.

The project is composed of five work packages (WPs), with sub tasks as presented below. Each task is defined so it also relates to a work package delivery. Data and information can be transferred to other WPs before final delivery, in order to reduce time. Partial deliveries will be coordinated between WP/task leads and project management. For each WP, milestones have been stated when applicable, to ensure project feasibility throughout the different phases.

WP 1 Project Management

WP 2 Development of Building Management Systems Auditing Process

WP 3 Development of a Software for Automated BMS Auditing and Continuous

Building Commissioning

WP 4 Demonstration of the Software in Case Study Buildings

WP 5 Project Results Dissemination

A shown in Fig. 6, all WPs are connected, and therefore work done in one WP is interrelated to other WPs. WP1 includes creation of detailed project activity plans, daily project management and coordination, project progress monitoring, risk management, project plan adjustment, periodic project reporting and writing of final project report. WP2 is dedicated to developing a systematic and comprehensive methodology for building management systems auditing, covering both initial commissioning and retrocommissioning of building management systems. WP3 deals with the software development, combining the BMS Auditing Process for initial and retro-commissioning of BMS developed in WP2 with the findings of the Online Building Energy Performance Monitoring and Evaluation Tool (ObepME) developed and demonstrated for building continuous commissioning. The developed set of tools are then implemented, demonstrated and evaluated in WP4, considering multiple case study buildings. WP5 is dedicated to the dissemination of the project's results, in both public and commercial interest, during the whole project period.

The specific deliverables of each WP are summarized below:

- WP1: This is the overall project management WP, including project planning, meetings, administrative reporting, partners coordination and resources and budget tracking.

- WP2: A list of technical specifications and functions of BMS to be audited and tested in addition to a holistic process for building management systems auditing to serve as a backbone for both initial BMS commissioning and retro-commissioning of upgraded BMS.

- WP3: A Combined BMS auditing and continuous building commissioning framework and a first of its kind software with a set of tools targeting building management systems auditing, initial- and retro-commissioning as well as whole building continuous commissioning.

- WP4: Demonstration and implementation of the developed software in multiple case study buildings, a comprehensive evaluation of the software for BMS initial 


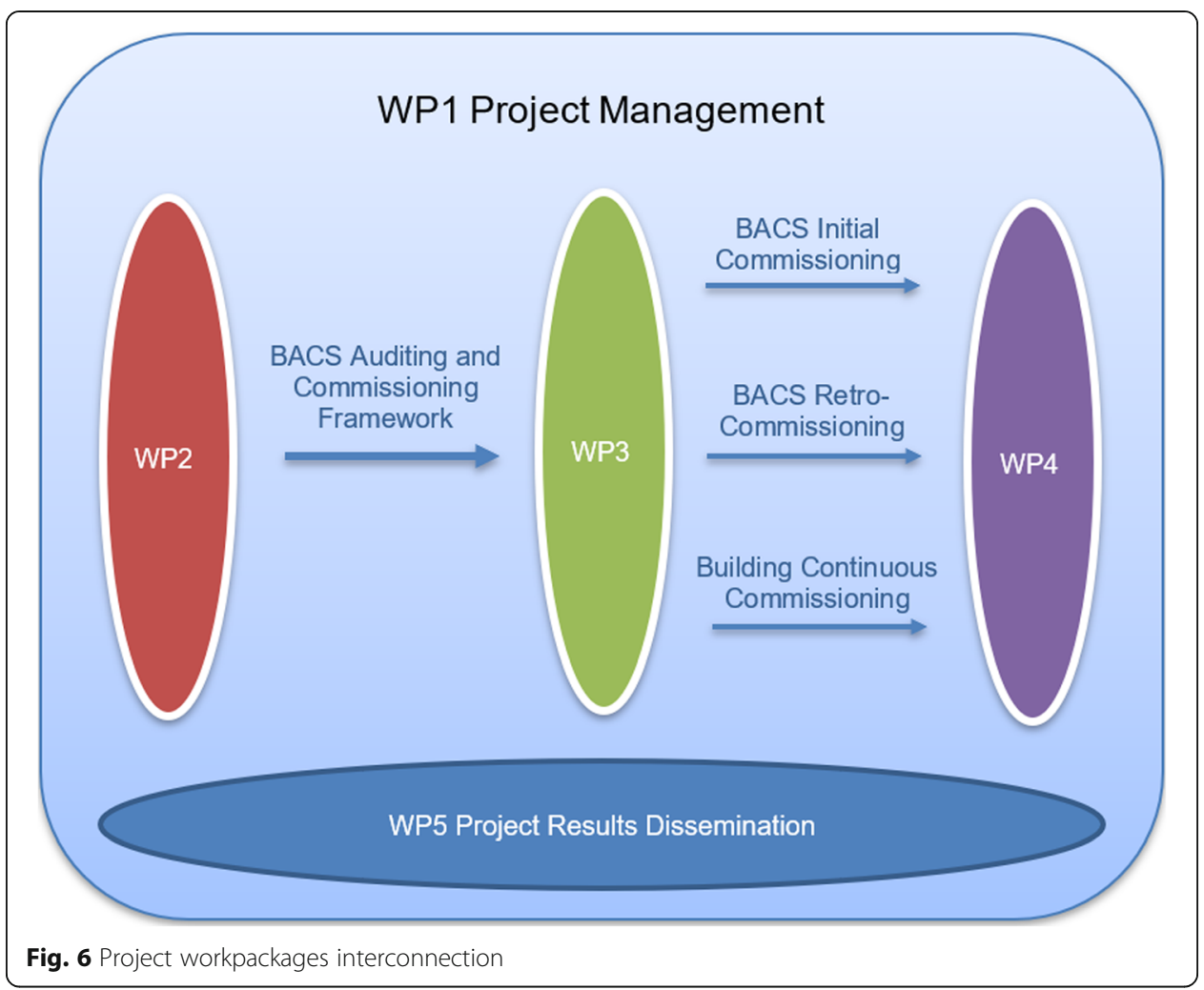

and retro- commissioning and building continuous commissioning along with building management system certification in the case studies considered based on the auditing implemented.

- WP5: project results and findings dissemination and communication to interested parties including research and academic network, public authorities and industrial companies in the field of energy in buildings, with newsletters, presentations, press releases, seminars, workshops, articles, and publications in reputed journals and international conferences.

\section{Project partners}

The project is carried out as a collaboration between academic, industrial partners and public bodies as presented in Fig. 7: Center for Energy Informatics (University of Southern Denmark), Schneider Electric Danmark, ReMoni, Sweco Danmark, Capital Region of Denmark, and Odense University Hospital. A steering committee will be formed with the responsibilities to oversee and ensure the project progress throughout the different phases in addition to monitoring and evaluating the progress of tasks and deliverables. The steering committee will ensure that the project is driven by the industrial needs at all times and will have direct and close contact during the project phases. The committee is also responsible for the coordination and communications between the different partners to ensure proper interaction and smooth collaboration.

The project is led by SDU Center for Energy Informatics, which is an interdisciplinary research center with expertise in development of innovative solutions for integrating and optimizing energy use with energy supply, considering technological, political, 


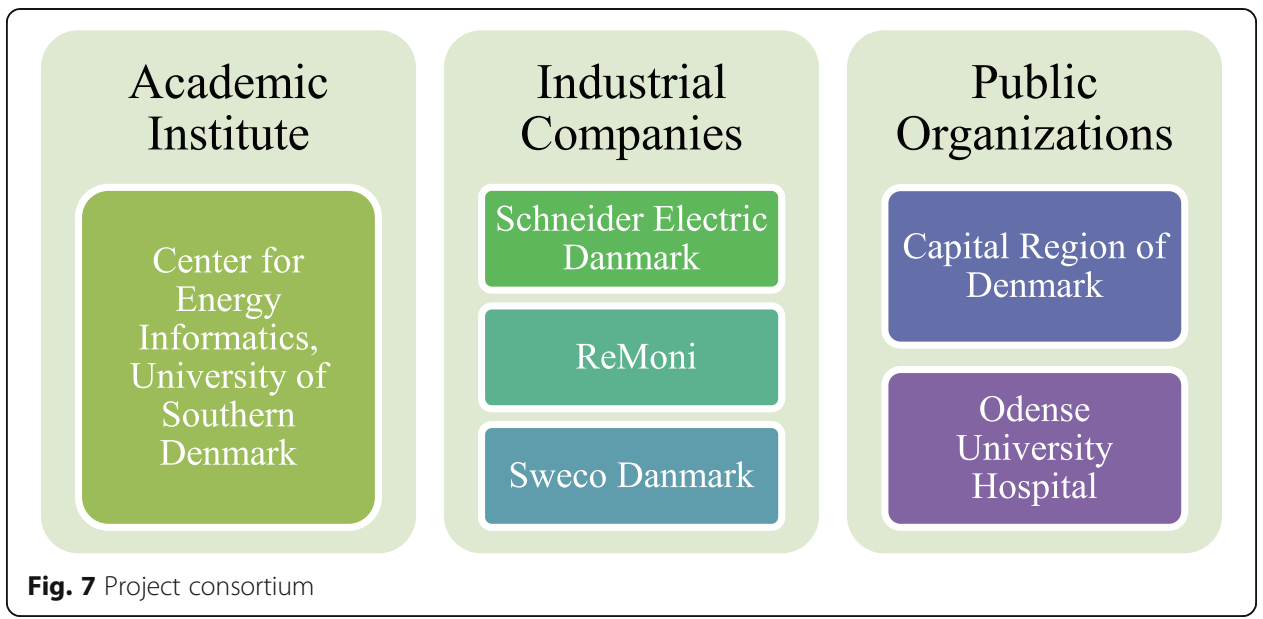

societal and economic framework conditions. The center has resources, competences, skills and experience in terms of building energy monitoring, benchmarking and performance evaluation, and employs experts within Computer Science, Software Engineering, Control Engineering, Building Physics, and Innovation Management. The first case study for the developed software demonstration is a selected building at SDU campus. SDU facility management department will contribute to this project in terms of preparing the building for testing and software implementation together with the SDU Center for Energy Informatics. The project manager is supported by experienced project administrator from SDU TEK-Innovation who is responsible for reporting to EUDP, and gathering the required data from the partners.

Schneider Electric is a world leader in the field of automation solutions, power management, energy management, spanning hardware, software, and services, with a global presence in over 100 countries. The company's main mission is to provide integrated efficiency solutions, combining energy, automation and software. The company is leading the global digital transformation of energy management and automation. Building management systems design, development and operation is one of the core competences where Schneider Electric is the world leading manufacturer and supplier. In this project, Schneider will collaborate with SDU in terms of developing and highlighting the major BMS specifications and functions to be targeted in the auditing and commissioning process as well as testing the developed auditing process. Moreover, Schneider Electric will collaborate with SDU and ReMoni on the development of the different tools, and take part in the demonstration of the software in the case study building.

ReMoni delivers the core technological platform for clamp-on measurements in the project: A cloud-based solution with low-cost, patent-protected clamp-on sensors and meters, wireless connected to the cloud. The novelty of its technology is that its sensor system enables the user to monitor power, flow and heat and cooling, simply by clamping sensor units onto cables, pipes, etc. without the need of technical intervention or disconnecting the system. In this project, ReMoni will have a major responsibility in the automation of the commissioning process and the development of the auditing and commissioning software along with taking part in the different case studies conducted within the project. ReMoni will implement and install their innovative sensing and metering technologies in the case study buildings to ensure proper data collection, as well as aiding data management and analysis. 
Sweco is a global leading company in the fields of architecture and engineering. This includes, design, development and operation of buildings, cities and communities. The company applications include building services, energy systems and units, infrastructure, architectural design, urban development and management services. Sweco will be majorly involved in the demonstration of the developed software in case study buildings with a main responsibility in buildings services and HVAC systems inspections, to collect information required for the auditing process.

The two partners Capital Region of Denmark and Odense University Hospital, and collaborator, Frederiksberg Kommune, are also at the same time end users of the developed software. They will lead the building preparation along with demonstration and testing, each for its own case study. An office building will be considered in Frederiksberg Kommune, Bornholms hospital will be considered in Region Hovedstaden and a selected building in OUH Svendborg will be selected to serve as a case study as well.

\section{Expected results and impact}

The major BuildCOM project outcome is the development and demonstration of an innovative first of its kind software for BMS automated auditing and continuous building commissioning. The software has three major capabilities, initial BMS auditing, BMS retro-commissioning and continuous building commissioning. The value proposition for the building owners is a guarantee that the building performs as expected with regard to energy efficiency, not only before the building is handed over but also continuously during operation and daily use. The direct benefits would be:

- Optimizing the energy performance of newly built and exiting buildings through ensuring a properly functioning building management system at the initial stage or throughout the building operation

- Reducing the energy consumption and improving the buildings energy flexibility quotient by ensuring high-level operation of the BMS while ensuring a smooth interaction and integration between various building components and energy systems

- Achieving operational costs savings and reductions in greenhouse gas emissions through implementing a continuous building commissioning process aiming to ensure a proper operation of the building throughout its operational phase while forming a backbone for a systematic fault detection and diagnostics framework.

The BuildCOM project builds up partly on the research findings and results of the international R\&D project COORDICY (COORDICY Project, n.d.), 'ICT-driven Coordination for Reaching 2020 Energy Efficiency Goals in Public and Commercial Buildings', in particular the development of an Online Energy Performance Monitoring and Evaluation Tool (ObepME), aiming to integrate the overall continuous commissioning tool within the new software to be developed in this project. The tool was developed within COORDICY by the Center for Energy Informatics at University of Southern Denmark in collaboration with Schneider Electric.

In Denmark, the government has set an ambitious target to achieve a fossil-free energy supply by 2050 and relying solely on renewable energy sources to cover the Danish 
energy demands (Lund \& Mathiesen, 2009). Thus, building energy requirements have been progressively tightened since the 1970s to reduce the overall energy consumption of buildings through forcing energy-efficient measures and standards (Danish Building Regultion BR18, n.d.). In addition, as a part of Denmark's energy agreement established in 2012, the largest ever comprehensive Danish energy renovation strategy was presented, "Strategy for the energy renovation of the existing building stock" (The Ministry of Climate, Energy and Building in Denmark, n.d.). Through developing and demonstrating the first-of-its kind innovative software for building management systems automated auditing and continuous building commissioning, this project will lead to substantial improvement in the overall energy performance of existing and newly built buildings. So, it contributes to the Danish goals of achieving a 75\% reduction in energy consumption in new buildings by 2020 and a 50\% reduction in existing buildings by 2050 (Lund \& Mathiesen, 2009).

In addition, the BuildCOM will support the recent EU building Directive 2018 (European Commission, 2018), with enhancing the design, operation and auditing of next generation building management systems. In the recent Directive (EU) 2018/844 of the European Parliament and of the Council of 30 May 2018 amending Directive 2010/31/EU on the energy performance of buildings and Directive 2012/27/EU on energy efficiency, the EU have set strict requirements regarding installing and assessing Building Management Systems.

Energy efficiency has been referred to as the best energy resource (Energy Efficiency is the best Energy Resource, n.d.). The direct impact of the project is to reduce the gap between real and predicted energy performance, to a value consistent with energy-efficiency standards, for buildings. In addition, the proposed software aims at ensuring a proper and energy efficient operation of the building systems from day one and throughout the building operational phase. This increase the energy efficiency and reduces the energy consumption of buildings which is about $40 \%$ of the total energy consumption today.

Moreover, the BuildCOM project contributes to the development of a fast-growing global market for building energy-management solutions, which is driven by energy efficiency policies, increasing energy prices, and an urgent need for cost savings. In 2017, the BMS market was poised to grow at a compound annual growth rate of around $16.7 \%$ until 2023. In 2023, the BMS market is expected to be valued at 19.25 billion USD, a drastic increase compared to only 6.65 billion USD in 2016. In a recent report by the European Commission entitled 'Smart Building: Energy efficiency application', an expected market growth of 15\% between 2015 and 2025 for smart buildings is reported. In addition, the number of smart home and smart building devices is forecasted to increase from 233 to 980 million units by 2025 (European Commission, 2017). This includes building energy management systems. In terms of the socio-economic importance, the Danish building sector has an overall employment of 350,000 including service and industry, and a total annual revenue of around 223.6 billion DKK (Iris Group, 2009).

A major target group for the project results and findings dissemination is building owners, including public buildings, offices, commercial buildings, hospitals, restaurants, university buildings and others, who will be interested in using the project findings to ensure that buildings perform as expected regarding energy efficiency, comfort and functionality. 
Schneider Electric expects to bring the project results to the market in the upcoming releases of their innovative EcoStruxure Building management platform. By automating the BMS auditing and commissioning process, Schneider Electric will be able to deliver a better product at a lower cost, with more cost-effective and energy efficient buildings along with better indoor environment to the benefit of the end customer and building user. Through proper design and automation of this process, Schneider Electric will be able to stand out of its competitors on quality without adding to the overall costs. The size of the Danish BMS market is estimated to be around 1.000-1.2000 Million DKK (Schneider Electric, Building Management Systems, n.d.). Schneider Electric's current share of the Danish market is estimated to be around 20\%. The technology will be implemented in new buildings and when major renovations are performed which corresponds to approximately half of Schneider's business within BMS systems. Thus, the market potential is estimated to be around 100-120 million DKK.

\section{Conclusion}

Aiming to meet the ambitious energy and environmental objectives for 2030 and 2050, the EU has prioritized the building sector highlighting the huge potential in achieving cost-effective energy savings and corresponding greenhouse gas emissions reduction. In this regard, the BuildCOM project is a timely action driven by the needs of the industry and customers and the increasing demands for energy efficiency, comfort, and safety in the buildings sector. While the whole energy sector, and the building sector in particular, is moving towards a holistic digitalization, building automation systems are expected to play a substantial role in attaining a smooth and effective transition. This report provides an overview on the BuildCOM project background work, aims, challenge targeted, approach and expected deliverables, serving as a basis for the project future activities.

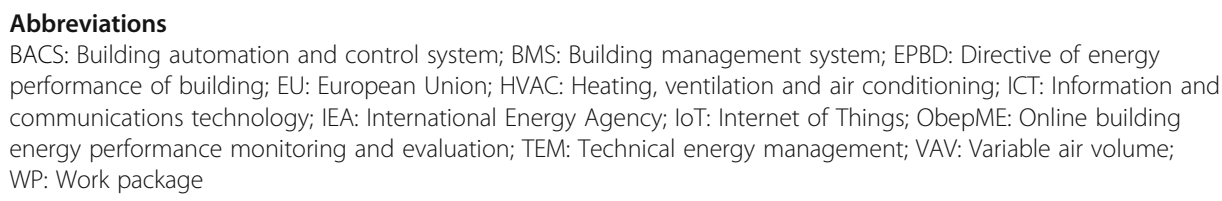

Acknowledgements

The authors would like to acknowledge Eirikur Benedikz from TEK Innovation, SDU Faculty of Engineering for his contributions in the writing process for the original project funding application.

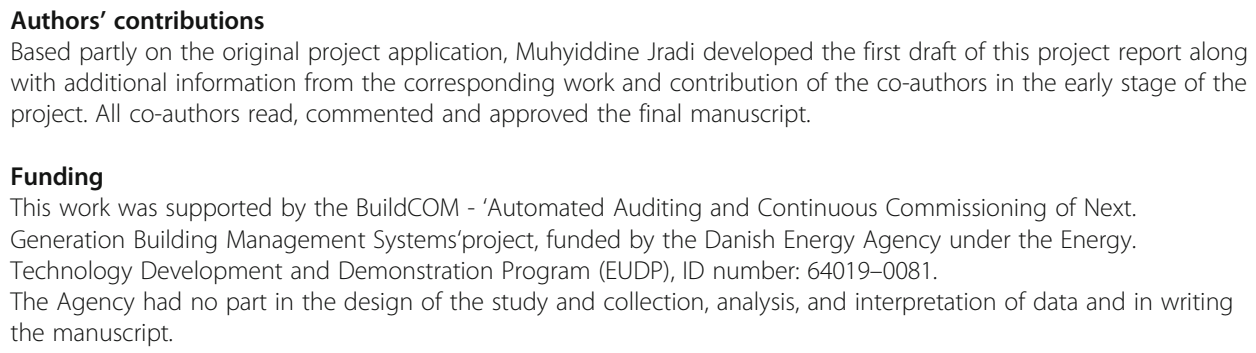

This work was supported by the BuildCOM - 'Automated Auditing and Continuous Commissioning of Next. Generation Building Management Systems'project, funded by the Danish Energy Agency under the Energy. Technology Development and Demonstration Program (EUDP), ID number: 64019-0081.

The Agency had no part in the design of the study and collection, analysis, and interpretation of data and in writing the manuscript.

Availability of data and materials

NA.

Competing interests

The authors declare that they have no competing interests.

\section{Author details}

${ }^{1}$ Center for Energy Informatics, Mærsk McKinney Møller Institute, University of Southern Denmark, Campusvej 55,

DK-5230 Odense M, Denmark. ${ }^{2}$ Schneider Electric Danmark A/S, Lautrupvang 1, DK-2750 Ballerup, Denmark. ${ }^{3}$ ReMoni, 
Industrivej 41E, DK-8660 Skanderborg, Denmark. ${ }^{4}$ Sweco Danmark A/S, Ørestads Boulevard 41, DK-2300 København, Denmark. ${ }^{5}$ Region Hovedstaden, Lyskær 13a, DK-2730 Herlev, Denmark. ${ }^{6}$ Odense Universitetshospital, Solfaldsvej 35, DK-5000 Odense, Denmark.

Received: 16 September 2020 Accepted: 4 December 2020

Published online: 13 January 2021

\section{References}

American Society of Heating, Refrigerating, Air-Conditioning Engineers (2006) The ASHRAE GreenGuide, The Design, Construction, and Operation of Sustainable Buildings, 2nd edn, pp 41-53

Aste N, Manfren M, Marenzi G (2017) Building automation and control systems and performance optimization: A framework for analysis. Renew Sustain Energy Rev 75:313-330

Building Management System Market by Software (Facility, Security, Energy, Emergency, Infrastructure Management), Service (Professional, Managed), Application (Residential, Commercial, Industrial), and Geography - Global Forecast to 2023. n.d.. https://www.reportsnreports.com/reports/1092858-building-management-system-market-by-software-facility-securityenergy-emergency-infrastructure-management-service-professional-managed-application-residential-commercialindustrial-and-geography-g-st-to-2023.html. Accessed 15 Oct 2020.

Bynum J, Claridge DE, Turner WD, Deng S, Wei G (2008) The cost-effectiveness of continuous commissioning over the past ten years. In: The 8th international conference for enhanced building operations. ICEBO, Berlin

COORDICY Project. n.d.. http://www.sdu.dk/en/om_sdu/institutter_centre/centreforenergyinformatics/research+projects/ coordicy. Accessed 21 Oct 2020

Danish Building Regultion BR18. n.d.. https://www.byggeriogenergi.dk/media/2202/danishbuildingregulations_2018_energyrequirements.pdf. Accessed 18 Oct 2020.

de Wilde $P$ (2014) The gap between predicted and measured energy performance of buildings: a framework for investigation. Autom Constr 41:40-49

Domingues P, Carreira P, Vieira R, Kastner W (2016) Building automation systems: Concepts and technology review. Comp Standards Interfaces 45:1-12, 2016/03/01

EN 152323 Standard. n.d.. http://www.buildup.eu/en/explore/links/overview-en-15232-standard-impact-building-automationcontrols-and-building-manageme-0. Accessed 18 Oct 2020.

Energy Efficiency is the best Energy Resource. n.d.. https://balkangreenenergynews.com/energy-efficiency-is-the-best-energyresource/

Engvang JA, Jradi M (2021) Auditing and design evaluation of building automation and control systems based on eu.Bac system audit - Danish case study. Energy Built Environ 2:34-44

European Building Automation and Controls Association (eu.bac). n.d.. https://www.eubac.org/home/index.html. Accessed 20 Oct 2020.

European Commission (2017) Digital transformation monitor smart building: energy efficiency application. https://ec.europa. eu/growth/tools-databases/dem/monitor/sites/default/files/DTM_Smart\%20building\%20-\%20energy\%20efficiency\%20v1. pdf. Accessed 13 Oct 2020.

European Commission (2018) Directive 2018/844 of the European Parliament and of the council of 30 may 2018 amending directive 2010/31/EU on the energy performance of buildings and directive 2012/27/EU on energy efficiency.

Evchina Y, Lastra JL (2018) An approach to combining related notifications in large-scale building management systems with a rehabilitation facility case study. Autom Constr 87:106-116

Frei B, Sagerschnig C, Gyalistras D (2017) Performance gaps in Swiss buildings: an analysis of conflicting objectives and mitigation strategies. Energy Procedia 122:421-426

GhaffarianHoseini A (2012) Ecologically sustainable design (ESD): theories, implementations and challenges towards intelligent building design development. Intell Build Int 4:34-48

Holbeck C (2007) Maximizing ROI in an Integrated BMS. https://www.buildings.com/article-details/articleid/5411/title/ maximizing-roi-in-an-integrated-bms. Accessed 18 Oct 2020

Ippolito MG, Riva Sanseverino E, Zizzo G (2014) Impact of building automation control systems and technical building management systems on the energy performance class of residential buildings: An Italian case study. Energy Build 69: $33-40,2014 / 02 / 01$

Iris Group (2009) Innovation af bæredygtige løsninger i byggeriet. https://irisgroup.dk/wp-content/uploads/2018/03/ Innovation-af-b\%C3\%A6redygtige-|\%C3\%B8sninger.pdf. Accessed 09 Oct 2020.

Jradi M, Arendt K, Sangogboye FC, Mattera CG, Markoska E, Kjærgaard MB, Veje C, Jørgensen BN (2018) ObepME: an online building energy performance monitoring and evaluation tool to reduce energy performance gaps. Energy Build 166:196-209

Jradi M, Liu N, Arendt K, Mattera CG (2020) An automated framework for buildings continuous commissioning and performance testing - A university building case study. J Build Eng 31:101464

Jradi M, Sangogboye FC, Mattera CG, Kjærgaard MB, Veje C, Jørgensen BN (2017) A world class energy Efficient University building by Danish 2020 standards. Energy Procedia 132:21-26

Lund H, Mathiesen BV (2009) Energy system analysis of 100\% renewable energy systems-the case of Denmark in years 2030 and 2050. Energy 34:524-531

Ma Z, Badi A, Jorgensen BN (2016) "Market opportunities and barriers for smart buildings", in 2016 IEEE Green Energy and Systems Conference (IGSEC), pp 1-6

Mancini F, Lo Basso G, de Santoli L (2019) Energy use in residential buildings: impact of building automation control systems on energy performance and flexibility. Energies 12:15

Markoska E, Jradi M, Jørgensen BN (2016) Continuous Commissioning of Buildings: A Case Study of a Campus Building in Denmark. Chengdu: IEEE International Conference on Internet of Things (iThings) and IEEE Green Computing and Communications (GreenCom) and IEEE Cyber, Physical and Social Computing (CPSCom) and IEEE Smart Data (SmartData); 2016. pp. 584-9. https://doi.org/10.1109/iThings-GreenCom-CPSCom-SmartData.2016.130.

Niu S, Pan W, Zhao Y (2016) A virtual reality integrated design approach to improving occupancy information integrity for closing the building energy performance gap. Sustain Cities Soc 27:275-286 
Ożadowicz A, Grela J (2016) An event-driven building energy management system enabling active demand side management. In: 2016 Second International Conference on Event-based Control, Communication, and Signal Processing (EBCCSP), pp 1-8

Ozadowicz A, Grela J (2017) Impact of building automation control systems on energy efficiency — University building case study. In: 2017 22nd IEEE International Conference on Emerging Technologies and Factory Automation (ETFA), pp 1-8

Petersen S, Hviid CA (2012) The European energy performance of buildings directive: comparison of calculated and actual energy use in a Danish office building, In: Proceedings of IBPSA-England first building simulation and optimisation conference (BSO), Loughborough

Rotger-Griful S, Welling U, Jacobsen RH (2017) Implementation of a building energy management system for residential demand response. Microprocess Microsyst 55:100-110

Schneider Electric, Building Management Systems. n.d.. https://www.se.com/ww/en/product-subcategory/1210-buildingmanagement-systems/. Accessed 17 Oct 2020.

Schönenberger P (2015) eu.bac System. Energy Build 100:16-19

Smart Readiness Indicator for Building, n.d.. vito, https://smartreadinessindicator.eu/

The Ministry of Climate, Energy and Building in Denmark, Strategy for energy renovation of Buildings: The route to energyefficient buildings in tomorrow's Denmark. n.d.. https://ec.europa.eu/energy/sites/ener/files/documents/2014_article4_ en_denmark.pdf. Accessed 13 Oct 2020.

Vigna I, Pernetti R, Pernigotto G, Gasparella A (2020) Analysis of the building smart readiness Indicator calculation: a comparative case-study with two panels of experts. Energies 13:2796

Zou PXW, Wagle D, Alam M (2019) Strategies for minimizing building energy performance gaps between the design intend and the reality. Energy Build 191:31-41

\section{Publisher's Note}

Springer Nature remains neutral with regard to jurisdictional claims in published maps and institutional affiliations.

\section{Submit your manuscript to a SpringerOpen ${ }^{\circ}$ journal and benefit from:}

- Convenient online submission

- Rigorous peer review

- Open access: articles freely available online

- High visibility within the field

- Retaining the copyright to your article

Submit your next manuscript at $\boldsymbol{\nabla}$ springeropen.com 